LUBLIN STUDIES IN MODERN LANGUAGES AND

LITERATURE 40(1), 2016, HTTP://WWW.LSMLL.UMCS.LUBLIN.PL, HTTP://LSMLL.JOURNALS.UMCS.PL

\author{
Alicja Dziedzic-Rawska \\ Maria Curie-Skłodowska University \\ Plac Marii Curie-Skłodowskiej 5, \\ 20-031 Lublin, Poland
}

\title{
Linguistic creativity in American prison settings
}

\begin{abstract}
Prison facilities are special: they are complexes defined by a variety of parameters, whose understanding for an ordinary person is far from perfect. It may be observed that two main cultures clash in prisons: that of jailers and that of inmates. Both groups have different rules of conduct, which results in many misunderstandings and new norms of behaviour created on a daily basis. This, in turn, gives way to a constant creation of unique vocabulary specific to the institution, its inhabitants and employees. It may be said that under such conditions prison language thrives: prison slang is extremely changeable and adapts itself to the current needs of the facility. Thus, the level of linguistic creativity is tremendously high: prisoners base their vocabulary loosely on similarities between animate and inanimate beings, which leads to the development of highly figurative language. The research undertaken here focuses on linguistic creativity in American prison settings, and by doing so, draws attention to the originality and unconventionality of prison slang.

Keywords: Conceptual Blending Theory; prison slang; linguistic creativity
\end{abstract}

1, Introduction

Linguistic creativity has been one of the notions in the foreground of linguistic interest. A couple of decades ago it was defined as the 
ability to produce infinitely many original utterances or sentences that are based on a limited number of lexemes and grammatical constructions (cf. Chomsky 1965). However, the fact that linguistic creativity entails much more than sentence construction has been duly noted, which can be seen from the sheer number of publications in this area. Chomsky himself notices that "an essential property of language is that it provides the means for expressing indefinitely many thoughts and for reacting appropriately in an indefinite range of new situations" (Chomsky 2014: 4). As new situations emerge on daily basis, there is a constant need to linguistically express new reality. Language gives its users proper means to accommodate to living conditions they currently experience; it is not only powerful in the fact that it provides us with words, but, as a cultural phenomenon, it has been marked as influencing the way we think (Whorf 1956). ${ }^{1}$

It may be valid to say that creativity equals nonconformity. Societies are dynamic and influenced by the surrounding reality and its changes. Societies develop and alter their norms and patterns of behaviour all the time. This, in turn, greatly affects the language being used to express our vision of reality. In case of internal conflict, i.e. if one does not accept one's reality, it is only natural that one wants to change it. Therefore, human beings, who are also language users unwilling to conform to social rules or to accepted norms of language use, are innovative when it comes to their linguistic behaviour. It is thanks to such language users that languages constantly develop and change. Because of the fact that prisons are facilities for people who find it difficult to adapt to mainstream conditions, the current work will focus on their language.

Language is manifestation. It is a manifestation of oneself; manifestation of one's culture; manifestation of belonging to a particular group, and/or manifestation of the view on reality and its particulars. Although people are similar in the way that they share

\footnotetext{
${ }^{1}$ Although Whorf's principle of relativity has been perceived as controversial (or even provocative), it has nevertheless shed light on the importance of language as a cognitive process.
} 
common cognitive abilities, the language they use varies depending on the culture they are part of, the conditions they live in, gender, age, beliefs, religion, environment, and many other factors. In each community, the language fulfils its task; members of the community adapt their language to their own needs. The various cultures of the world have different categories, thus different perception of reality the language to describe it. In prisons, where special norms operate, the language used is adjusted to the setting and appropriate contexts. Prisoners bind themselves emotionally with the facility or the prison group/subculture they belong to, e.g. by having an unofficial inmate code that guides their conduct. The inmate code is of crucial importance inside prison: it is like the Bible to a Christian. It is treated seriously and in many cases is the direct reason for rejecting rehabilitation. Nevertheless, the inmate code is one of the key factors contributing to the formation of prison slang. One of the rules says not to trust the authority: the authority is wrong and the prisoners are right. This openly allows prisoners to develop negative feelings towards guards, and this, in turn, results in many terms depicting the latter (e.g. screw, babysitter, white shirt, footballer, etc.).

Language has a social function", which means that "the language spoken by a group of people is related to that group's social position and organization" (Barker 1945: 228). In the prison setting, social position is based on a strict hierarchy, mostly without the possibility of change. Prison, a place of detention for a range of offences, is a facility with complex rules and regulations, which, in turn, give way to more complex hierarchy and relationships between jailers and inmates. There is a constant struggle for power, which is not only reflected in the behaviour of prisoners, but also in the language used. Prisons contain numerous subcultures or gangs, each of them having their own name, e.g. A.B., European Kindred, Hell's Angels MC, Sons of Silence or United Blood Nation. Belonging to the same prison group not only binds prisoners on an emotional level, but also allows

${ }^{2}$ There exist other functions of language, whose analysis lies beyond the scope of this work. 
them to create their own variations of prison slang. Prison groups often compete: each of them has their own set of values and norms, each of them occupies itself with something different, and each of them gives roles to its members, e.g. merchants deal with cigarette trade, gorillas pray on the weak inmates, and heads use drugs. It seems that assigning roles helps prisoners to organize and understand the prison world.

Studies pertaining to linguistic creativity in relation to culture or particular communities are rather scarce. Even more limited is the research on linguistic creativity in any prison setting. No such publications have been found for the writing of the current paper. However, as Langacker puts it (2014: 47),

language is a mental and a sociocultural phenomenon. Despite their divergent agendas, relevant disciplines should all be concerned with an integrated account of language, culture, and cognition, for these are by nature indissociable.

Analysing language with no account of the socio-cultural phenomena associated with it seems rather facile. Therefore, the current paper will view the notion of linguistic creativity in American prisons, with a consideration of prison culture and prison setting.

The paper will be organised as follows: first, some background of prison slang formation will be presented together with the data sources; then this will be followed by the analysis of two American examples, and finally conclusions will be drawn.

\section{Linguistic creativity in the prison setting}

In the 'linguistic melting pot' (Musgrave \& Burridge, 2014: 3), there is a place for slang, as one of the ingredients which cannot be ignored or substituted. Nevertheless, despite the fact that slang is an integral part of our linguistic life, it has not been worthy of scholarly intense attention, which is visible in the number of publications in this area. However, this fact should not be surprising as access to prisons is limited or even impossible. Even once inside, a scholar has no

${ }^{3}$ By this, the authors mean a collection of non-standard vocabularies, like dialects or slang. 
guarantee that what he learns is in any sense relevant. Underhill stresses that "the insight of the insider is precious" (2011: 133), which is in line with sociological and anthropological view on studying human beings, their language and culture. ${ }^{4}$ Nevertheless, Polish scholars who succeeded in studying prison culture from inside stress that it is almost impenetrable, reserved or even hostile. ${ }^{5}$ In such cases, scholars may make use of the available sources in the form of dictionaries, articles, books, or online materials. For the current study, two main sources have been used: Green's Dictionary of Slang (2010) (henceforth GDS) and http://law.jrank.org/pages/1796/PrisonsPrisoners-Inmate-subcultures-informal-organizations.html (access 24.02.2016)

Isolated by prison walls, prisoners are not constrained by any rules pertaining to language, other than the fundamental properties of language as such. They may choose to make use of the rules they are familiar with, or they may create forms they please, since often they are alone responsible for organizing the surrounding reality from the scratch. Therefore, their level of linguistic creativity is, without a doubt, very high. Di Pietro says that "creativity is very much a part of modern man's language abilities and is intimately connected with his physical and psychic being" (1971: 68). Under the special circumstances of prison walls, it is inseparable to learn the conditions the prisoners live in and to detail their portrayal of their world. Presenting the 'objective' understanding of prison language entails studying all characteristics of prisons, their regulations and culture, the personalities and the behaviour of prisoners, and many other factors, for "may not objectivity be defined as the composite picture gained by laying a number of subjectivities on top of one another ...?" (Sapir 1917: 504).

\footnotetext{
${ }^{4}$ Both sociology and anthropology call it 'participant observation', the principle of fieldwork proposed by Malinowski.

${ }^{5}$ E.g. Marek Kamiński’s Games Prisoners Play, or Kamil Miszewski's Sociolog w kryminale: więzienie jako nieprzyjazny teren badań [ENG A sociologist in jail: prison as a hostile research area] [translation my own]
} 
3. Samples and discussion

"It goes without saying that the mere content of language is intimately related to culture" (Sapir 2004 [1921]: 181). The choice of the language prisoners use, and any language outside of prisons for that matter, is not arbitrary. Linguistic creativity in prison setting is taken onto a whole new level. At some point, especially when prison slang is simply adopted by a new inmate, the process may or may not be entirely conscious; there is no consideration given as to how a particular expression emerges, and, mostly, the etymology is lost in time. Prisoners make use of the language we all know; nevertheless, very often they give the language new meanings or construct completely new words. The reasons for doing so are numerous: firstly, they feel an inner need to have their own language variety, to linguistically express themselves, and, thus, to be distinguished in contrast to others; secondly, through language they can camouflage their true intentions; thirdly, they want to manifest their culture/subculture as distinct; fourthly, they want to encapsulate their own view of the world, and, fifthly, to linguistically organize their own reality in order to better understand, relate and react to it. Sapir was more than aware of the fact that different societies of the world may have non-identical worldviews, as he stated that "the worlds in which different societies live are distinct worlds, not merely the same world with different labels attached" (1929: 209). Thus, to analyse, at least partially, the language of any society, it is necessary to understand that their reality will be differently perceived and named. Therefore, the perception of the prison world cannot be put on a par with our own.

Prisons can be viewed autonomously, being only partially influenced by the outside world. That is why, the language used inside the prison walls thrives. Prisoners name everything as they please, from objects to people and their actions. In learning something of the prison world, of the system the prisoners are part of, language is more than helpful. This can happen through exposure to the reality or actually through language. Language is, thus, not only a means into the creative mind of the prisoners but it also represents their social 
reality. For the following work, as a thorough analysis of the prison slang is impossible given the limitations of space, only two expressions will be analysed in the remainder of this paper: air dance and brake fluid.

\subsection{Air dance 'a hanging'}

Psychologists claim that, if persistent enough, we can always detect similarities between the thing we compare with something we compare it to. ${ }^{6}$ In dealing with slang, especially the slang used by prisoners, those similarities will be far-fetched; they will not be obviously recognizable as prison slang is only understood by its users. Nevertheless, a linguist equipped with theoretical descriptive tools has a very good chance of disassembling any phrase or word into analysable pieces. One of such tools is Fauconnier and Turner's Conceptual Blending Theory (CBT) used to analyse meaning construction. The theory assumes that, in everyday thinking and language use, there is a mental operation of creating a number of mental spaces that serve as input spaces for a complex meaning encapsulated in their unique combination, a blended space. In meaning formation, elements from input spaces are mentally joined; there is also a generic space containing elements from both input spaces. Input spaces are connected into the fourth one that, importantly, contains a new element not directly present in any of the inputs. In the present analysis, CBT will be shown to contribute to our interpretation of the expressions being investigated.

The expression air dance, the conceptual metaphor DANCE FOR DEATH, is an instance of vivid imagery. The image evoked here is that of a hangman's legs moving in the way that brings to mind the legs of a dancer. Upon hanging, before all life symptoms are lost, there is a supposedly violent struggle of the person, which causes legs, arms, and the whole body to move - this suggests resemblance to dance moves. The component air is clear: hangman's legs do not touch the ground; they 'dance' in the air. Other prison variations of

\footnotetext{
${ }^{6}$ See e.g. Maruszewski 1996.
} 
this compound are air jig and air polka. The term dance as 'a hanging' has existed in slang, according to GDS, since c.1535, but the last printed use of it was observed in 1979. Therefore, the prison expression can be seen as a partial re-introduction.

Air dance is an example of a blend; however, in order to unveil its details, the conventional metaphorical mappings will first be presented. Nonetheless, as this metaphor is not used in popular discourse, the cross-domain correspondences discussed below may not be complete. For that, it would be indispensable to be familiar with the totality of the context, ${ }^{7}$ the lives of prisoners and their reality.

Dance

Steps/ movements to music

Form of sport/hobby/art

Brings happiness

Rhythm

Movement in lively manner
Hanging

Movement of body

Form of punishment

End of life

Body moves in a particular way?

Movement in lively manner as a struggle

GDS provides an example sentence of the metaphor use as a 2005 post in a guitar forum, whose validity is unattestable as the post has probably been removed and is no longer traceable.

1) time to give them $\mathrm{f}^{*} \% \# @{ }^{\wedge} \mathrm{g}$ clowns a necktie party and watch them do the air dance!!!! just give me the word - I'll bring the rope!

Grady et al. say that Blending Theory (henceforth BT) also allows that "selective projection from the two input spaces yields an image which is inconsistent with our understanding of the source space" (1999:111112). This is corroborated by the example given here: the image of a dance is mapped onto the image of a death, especially taking place in prison setting. Later, in the same passage, the authors state that "the

${ }^{7}$ Including, but not limited to, the speakers involved, the act of hanging, how and where it is performed, the exact situation resulting in the act, the time of hanging, etc. 
web of underlying connections allow us to draw inferences from the blend" (ibid.: 112). However, in my opinion this fact cannot be accounted for with a metaphor as air dance.

Figure 1 presents a possible blend analysis of this expression.

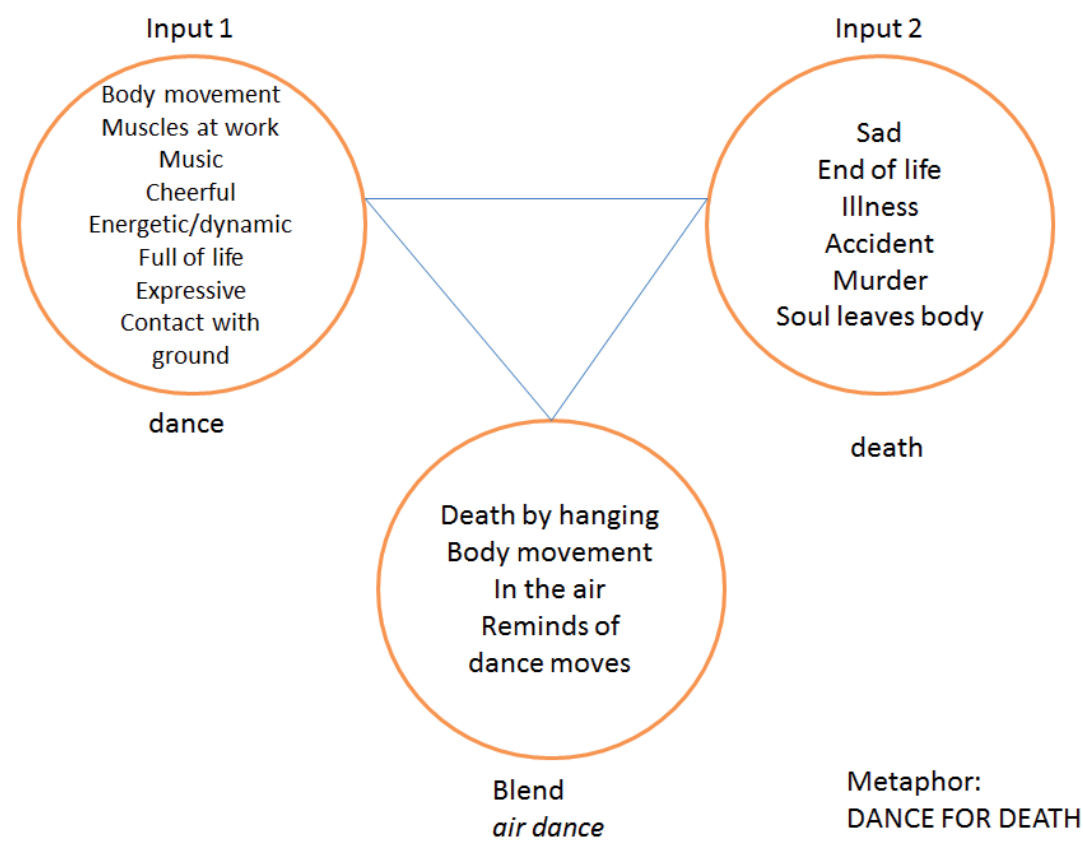

Figure 1. Blend analysis of air dance.

At this point, it should be noted that a positively valued term like dance is placed in a negative context, and it only acquires negative emotions once it is used in the prison setting. Additionally, it can be assumed that the expression is a sign of mockery, as sources claim that human life has little value to prisoners (see e.g. the hierarchy in prison presented by Vaughn and Sapp 1989, in murderers clearly occupy a high position). The compound air dance is understood 
outside prison as the type of acrobatic modern dance performed suspended with the use of a concealed harness and a rope, a fabric, or a trapeze. In modern slang, it is, however, a provocative female dance at a strip club without bodily contact with the customer. ${ }^{8}$ Nevertheless, it is uncertain if the prison term is in any way related to the one used in standard English. However, because it is implied that legs or the whole body move as if dancing, it may be assumed that the expression relates to suicides or a form of killing performed by other prisoners. Online sources say that a professional hanging is a well-calculated act, where no, or almost no, body movement can be observed. ${ }^{9}$

3.2. Brake fluid "psychiatric meds used to tranquilize a patient" As in the case of air dance, this expression, once it is used outside standard context, loses its transparency. Prison slang is especially designed for such purposes: it has no intention of being open to anyone as its main purpose is not to reveal any confidential information. ${ }^{10}$ That is the reason why most of the meaning familiar to users of standard forms of the language gets modified and is adjusted to prison reality and the subjective needs of prisoners.

Prior to the analysis of the blend, it is worth focusing on the crossdomain correspondences in order to shed light on the mapping between two input spaces: car brakes and psychiatric medicines.

Car brakes

For cars

Slow or stop car

Metal

Indispensable part
Psychiatric medicines

For people

Slow or stop aggression in patient

Liquid/pill

Indispensable with aggressive patients

\footnotetext{
${ }^{8}$ Source: http://www.urbandictionary.com/define.php?term=Air+Dance

${ }^{9}$ Nonetheless, the validity of the statement should be confirmed with medical specialists or other experts.

${ }^{10}$ This has also been observed e.g. by Halliday in his famous Anti-Languages.
} 
The intended meaning of the compound is medicine, preferably in the form of liquid, ${ }^{11}$ that is supposed to calm an unstrung patient. Just like the purpose of a car brake, fluid is to make parts of brakes operate smoothly and without disturbance, the purpose of psychiatric pharmaceuticals is to metaphorically make a patient 'run' smoothly, i.e. preventing or easing any nervous breakdowns or other psychological conditions. What is more, a healthy person is naturally gifted in a restraint, a metaphorical brake that controls him in a perilous or an unsuitable situation, whereas a person with a mental disorder is deprived of it and must be medicated. Additionally, as prison slang often capitalizes on pronunciation, it is worth noting that brake is a homophone of break. If this fact is taken into account, then the meaning becomes a bit more transparent. According to oxforddictionaries.com, the verb to break means, i.a., 'to put an end to sth', 'to make a pause' or 'to stop oneself being subject to'; the noun $a$ break 'an interruption', 'a pause', 'an interval', 'a holiday', or even 'an escape', all indicating temporal or permanent time off from any circumstances one might be exposed to.

Interestingly enough, the context in which this compound appears is not helpful at all, as prison slang is abundant in expressions whose meaning is incomprehensible for an ordinary user of standard English.

2) Bill's an old head square john gone crazy from drinking pruno; the man's got him on brake fluid. ${ }^{12}$

Without the proper knowledge of prison language and setting, it is impossible to read old head as 'middle-aged or elderly inmate', square john as 'middle-class, conventional inmates who identifies with staff members' or pruno as 'homemade jailhouse alcohol'. Therefore, the sense of the whole utterance is obscured. Nevertheless, a linguist has in their disposal certain tools, e.g. the theory of

\footnotetext{
${ }_{11}^{11}$ E.g. Valerin, a relaxant often prescribed in hospitals. http://law.jrank.org/pages/1796/Prisons-Prisoners-Inmate-subcultures-informalorganizations.html (access 25.02.2016)
} 
blending, which come in handy when dealing with such nontransparent expressions.

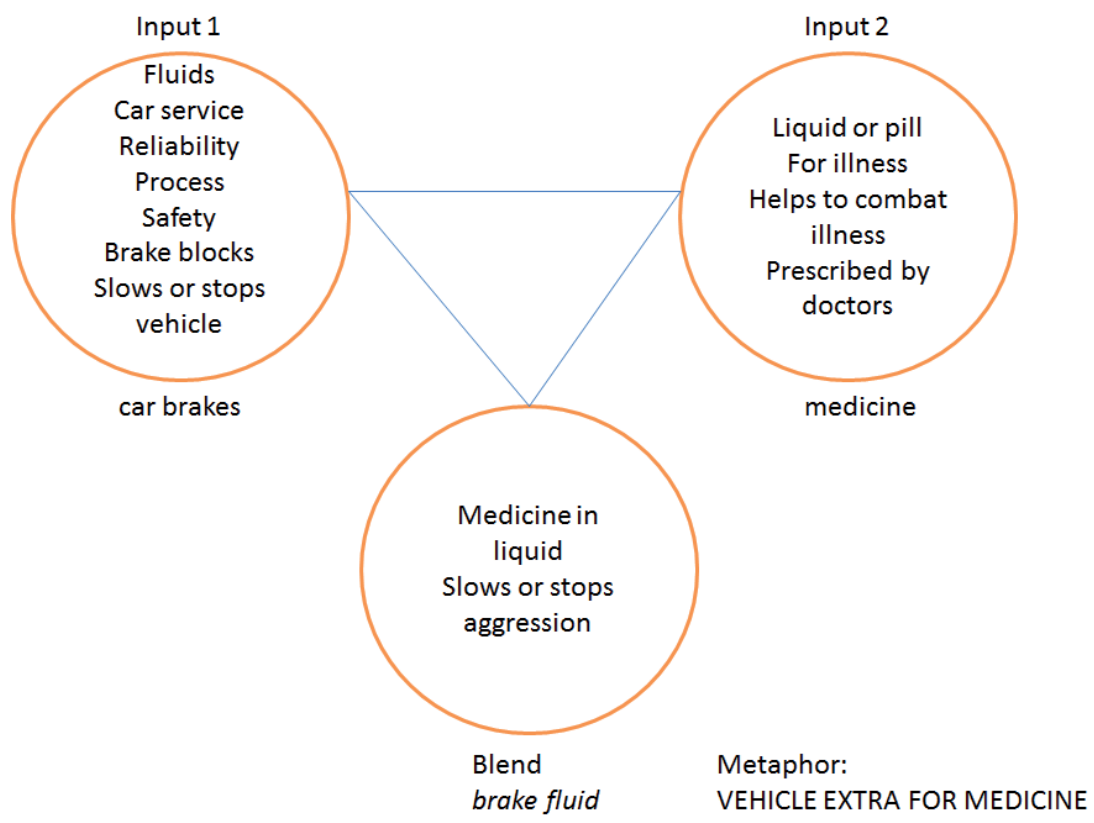

Figure 2. Blend analysis of brake fluid.

All metaphors, including those used in prison context, appear in particular situations, in which both the speaker and addressee participate in an event, in which the metaphor used serves a specific purpose. Given the context outside prison, the participants in a conversation very likely have access to the same knowledge of the world and the language they use. According to Brandt and Brandt (2005: 219),

the semantic content, which is inherently intersubjective, born of the speaker's intention to have the addressee recognize his utterance as an attempt to engage in 
a semiotic event of shared attention, as well as its pragmatic implications [...] constitute the meaning of a metaphor.

Later the authors state that in metaphor analysis "it is $[\ldots]$ inconsequential [...] whether it is conducted from the perspective of a the speaker or addressee, as the mental content is shared" (ibid.) [emphasis added]. In prison setting, it is crucial that the knowledge is shared by the members of the same group, as the meaning of a particular word/phrase may be entirely different in another group's slang. How a particular utterance is evaluated is a result of many various parameters, e.g. the context, the knowledge of the participants (background and contemporary), the communicative situation or the status of the participants.

\section{Conclusions}

Prison slang is extremely rich and creative. New vocabulary items are being formed on a daily basis. A word that is formed today is outdated tomorrow. Meanings change all the time, and the pace of the changes is hard to follow. For these reasons, prison slang definitely deserves linguistic attention as it is an example of language users' high linguistic creativity. It manifests itself in extreme figurativeness, including the use of metaphor and metonymy (the latter of which has not been discussed here due to limitations of space). A thorough analysis would require many more examples; however, the current work draws us one step closer to constructing an appropriate view of the situation.

An old English idioms says: "When in Rome, do as the Romans do". Jim Thomas claims that "as in any culture, the better one expresses the language, the more 'assimilated' one is presumed to be." (http://jthomasniu.org/class/388/lecture/code.inmate) (access 18.02.2016) When functioning in a given culture, one needs to acquire, not only accepted norms, beliefs, behaviours, but also language, which is part of any process of socialization. In prison setting, the decision whether a prisoner can become a full-member of any prison group is based upon, among other things, that prisoner's 
command of the prison lingo. Membership very often depends on a successful use of the language.

One of the most important reasons of developing prison slang is its high level of figurativeness, thanks to which hiding true meanings is relatively easy. Only by the use of metaphors, abbreviations, and other linguistic means, can prisoners secure themselves against unauthorized party receiving their messages. Doing so is often the only means of surviving in prison; therefore, linguistic creativity is very useful. Semantic alterations guarantee illegibility of an utterance to a third party.

Martin Haspelmath says that, every now and then, speakers "want their utterance to be imaginative and vivid - they want to be little 'extravagant poets' in order to be noticed, at least occasionally" (Haspelmath 1999, in Duffley 2013: 59). Combined with prison setting, this imagination and vividness achieve a new status: nontransparency. In order not to arouse suspicion, prisoners often use old terms with new meanings. In addition, prison slang is characterized by a high degree of mockery, imagery, insults, irony (e.g. pant worm 'the penis'), which are mainly realised by the use of figurative language.

Prison slang has been formed as a response to prison environment. As prisons are composed of many different elements whose relative imports influence and penetrate one another (prisoners, wardens, jailers, hierarchy, regulations, cells, ethnic groups, etc.), language must adapt itself to the needs of prisoners in the specific (kind of) facility. Everyday situations force prisoners to code their messages in a language reflective of the current context. Language is part of any culture, it is reflective of the worldviews language users have and, it influences the way they think. Thanks to the vivid changes any language undergoes, cultures change. Therefore, I feel that, following Sahlin's words, "culture is neither what it was before nor what it could have been" (2004: 220).

References

Barker, George C. (1945). The social functions of language. ETC.: A Review of General Semantics 2, 228-234. 
Brandt, Line, \& Per Aage Brandt (2005). Making sense of a blend: A cognitivesemiotic approach to metaphor. Annual Review of Cognitive Linguistics 3(1), 216249.

Chomsky, Noam. (2014 [1965]). Aspects of the Theory of Syntax. No. 11. Cambridge, Massachusetts: MIT Press.

Di Pietro, Robert J. (1971). Contrastive analysis and linguistic creativity. Working Papers in Linguistics 3(4), 57-71.

Duffley, Patrick J. (2013). How creativity strains conventionality in the use of idiomatic expressions. In M. Borkent et al. (eds.), Language and the Creative Mind. Stanford: CSLI Publications, 49-61.

Grady, Joseph, Todd Oakley, \& Seana Coulson (1999). Blending and metaphor. Amsterdam Studies in the Theory and History of Linguistic Science Series 4, 101124.

Green, Jonathon (2010). Green's Dictionary of Slang. London: Chambers Harrap Publishers.

Halliday, Michael Alexander Kirkwood (1976). Anti-languages. American Anthropologist 78(3), 570-584.

Kaminski, Marek M. (2010). Games Prisoners Play: The Tragicomic Worlds of Polish Prison. Princeton: Princeton University Press.

Langacker, Ronald (2014). Culture and cognition, lexicon and grammar. In M. Yamaguchi et al. (eds.), Approaches to Language, Culture, and Cognition. Basingstoke: Palgrave Macmillan, 27-49.

Maruszewski, Tomasz (1996). Psychologia poznawcza. Znak-Język-Rzeczywistość. Warszawa: Polskie Towarzystwo Semiotyczne.

Miszewski, Kamil (2005). Socjolog w kryminale: więzienie jako nieprzyjazny teren badań. Studia Socjologiczne 3, 65-92.

Musgrave, Simon, \& Kate Burridge (2014). Bastards and buggers. Historical snapshots of Australian English swearing patterns. In K. Burridge and R. Benczes (eds.), Wrestling with Words and Meanings. Clayton: Monash University Publishing, 3-32.

Sahlins, Marshall (2004). Apologies to Thucydides: Understanding History as Culture and Vice Versa. Chicago: University of Chicago Press.

Sapir, Edward (2004 [1921]). Language. An Introduction to the Study of Speech. New York: Dover Publications.

Sapir, Edward (1929). The status of linguistics as a science. Language 5(4), 207-214.

Underhill, James (2011). Creating Worldviews: Metaphor, Ideology and Language. Edinburgh: Edinburgh University Press. 
Vaughn, Michael S., \& Allen D. Sapp (1989). Less than utopian: Sex offender treatment in a milieu of power struggles, status positioning, and inmate manipulation in state correctional institutions. The Prison Journal 69(2), 73-89.

Whorf, Benjamin Lee (1956). Language, Thought, and Reality (John B. Carroll, Ed.). New York: John Wiley \& Sons. 